
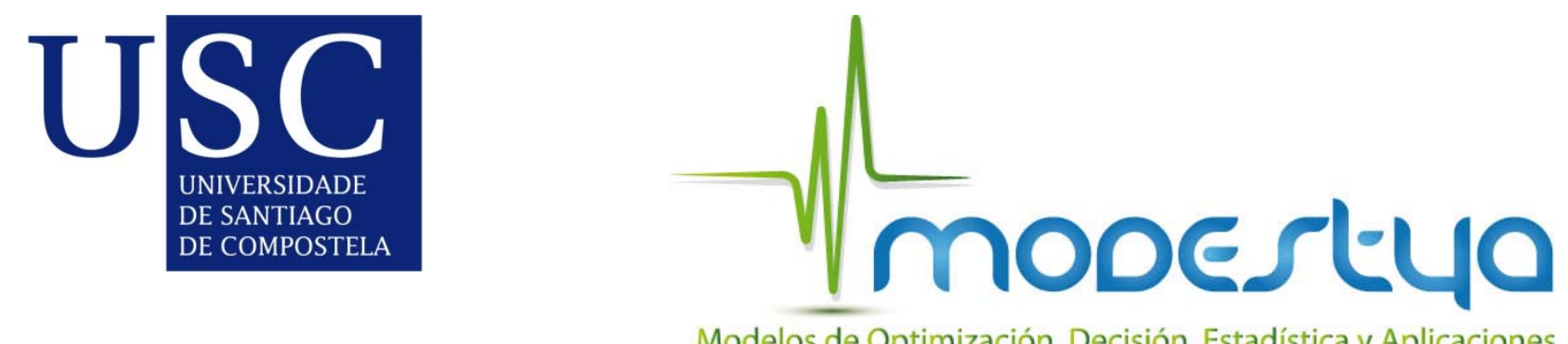

\title{
Validation of an AutoRegressive Integrated Moving Average Model for the Prediction of Animal Zone Temperature in a Weaned Piglet Building
}

J .A. Ortega, E. Losada, R. Besteiro, T. Arango, M.J . GinzoVilla mayor, R. Velo, M.D. Femández, M. R. Rodríguez

Version: Accepted manuscript

\section{HOW TO CITE}

Ortega, J A., Losa da, E., Besteiro Doval, R., Arango López, T., Ginzo-Villamayor, M.J ., Velo Sa bín, R, Femández Rodríguez, MD., Rodriguez Rodríguez, MR. (2018). Validation of an AutoRegressive Integrated Moving Average model for the prediction of a nimal zone temperature in a weaned piglet building Biosystems Engineering. 174. pp. 231238. Elsevier.

\section{PUNDING}

The authorsare grateful to the regional govemment Xunta de Galicia for funding this research through the "Programme of consolidation and structuring of competitive research units" (G PC 2014/072). 
1 Validation of an AutoRegressive Integrated Moving Average Model

2 for the Prediction of Animal Zone Temperature in a Weaned Piglet

\section{Building}

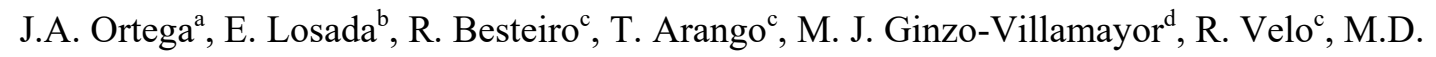

Fernandez ${ }^{\mathrm{c}}$, M.R. Rodríguez ${ }^{\mathrm{c*}}$

$6 \quad{ }^{a}$ Xunta de Galicia, Regional Agrarian Office of Lalín, Pontevedra, Spain

$7 \quad{ }^{b}$ Xunta de Galicia, Department of Culture, Education and University Planning, Lugo, Spain

$8 \quad{ }^{\mathrm{c}}$ Department of Agroforestry Engineering, University of Santiago de Compostela, Campus

9 Terra, 27002, Lugo, Spain

${ }^{\mathrm{d}}$ Department of Statistics, Mathematical Analysis and Optimization, University of Santiago de

11 Compostela, Faculty of Mathematics, Campus Vida, 15782 Santiago de Compostela, Spain.

*corresponding author: manuelramiro.rodriguez@usc.es

\section{Abstract}

An AutoRegressive Integrated Moving Average model was validated for the prediction of temperatures in the animal zone of conventional weaned piglet barn. The validation period covered seven cycles and recorded values at 10-min intervals for 292 days. Average weight was $5.75 \pm 0.86 \mathrm{~kg}$ at the beginning of the production cycle and $18.41 \pm 2.12 \mathrm{~kg}$ at the end of the cycle. Mean outdoor air temperatures ranged 6.14 to $17.85^{\circ} \mathrm{C}$ with deviations in the range $2.49^{\circ} \mathrm{C}$ to $5.24^{\circ} \mathrm{C}$, which involved marked differences in the operation of the ventilation system. The Mean Average Percentage Error was below $4 \%$, with a mean error of $\leq 1^{\circ} \mathrm{C}$. The Root Mean Square Error was in the range $0.77^{\circ} \mathrm{C}$ to $1.19^{\circ} \mathrm{C}$, whereas the coefficient of determination ranged between 0.52 and 0.81. Despite the changes in environmental conditions and in animal weight and management, the accuracy of the model remained stable with low dispersion of values. 
1 The model showed good accuracy and reliability covering all the seasons under changing

2 meteorological conditions because it considered the operation of the heating and

3 ventilation systems and changes in animal weight. The residuals obtained from the

4 validation of the seven production cycles were Gaussian distributed, which confirmed the

5 validity of the model. The generated model can be used for more effective environmental

6 control systems that are capable of anticipating events and show a better response, which

7 helps improve energy savings and animal welfare.

8

9 Keywords: weaned piglets; ARIMA; validation; temperature; indoor climate; livestock 10 buildings.

12 Nomenclature

13 ARIMA AutoRegressive Integrated Moving Average

14 CFD Computational Fluid Dynamics

$15 \operatorname{COV}_{X \tilde{X}} \quad$ covariance of $X$ and $\tilde{X}$

$16 d$ backshifts for degree of differencing of the ARIMA model structure

17 MAPE Mean Absolute Percentage Error, \%

$18 \quad M E \quad$ Mean Error

19 number of records

$20 p \quad$ backshifts for lag order of the ARIMA model structure

$21 q$ backshifts for averaging window of the ARIMA model structure

$22 R^{2}$

coefficient of determination

23 RMSE Root Mean Square Error

$24 \quad S_{a o} \quad$ air outlet section area, $\mathrm{m}^{2}$

$25 S D \quad$ standard deviation 


$\begin{array}{ccl}1 & T_{a o} & \text { outdoor air temperature, }{ }^{\circ} \mathrm{C} \\ 2 & T_{a z} & \text { animal zone temperature, }{ }^{\circ} \mathrm{C} \\ 3 & V_{a o} & \text { volume of extracted air by the fan, } \mathrm{m}^{3} \\ 4 & W_{a} & \text { body mass of the animals, } \mathrm{kg} \\ 5 & X_{t} & \text { value measured at time } t \\ 6 & \tilde{X}_{t} & \text { value predicted by the model at time } t \\ 7 & \sigma_{X} & \text { standard deviation of } X \\ 8 & \sigma_{\tilde{X}} & \text { standard deviation of } \tilde{X} \\ 9 & & \end{array}$

\section{Introduction}

The increasingly restrictive environmental and animal welfare regulations for the pig industry, along with the increase in energy demand, have significant effects on farm competitiveness and environment. In this context, the productivity of farms must be improved, which calls for an improvement in energy efficiency and animal welfare. sensitive phases of swine production and the phases with the highest energy requirements (Dolz et al., 2015). Weaning in particular is a sensitive phase characterised by simultaneous stresses including separation from the sow, mixing of litters, and changes in diet and environment (Le Dividich \& Herpin, 1994; Dong \& Pluske, 2007). During weaning, piglet weight triples over a short period, animal welfare demands are strong, and the climatic demands of the piglets show important variations. Consequently, environmental control systems must be adapted to the growth needs of piglets. 
Models for the prediction of environmental variables in diverse scenarios require extensive validation before use. Moreover, the global increase in temperature caused by climate change demands flexible and adaptable models that provide error estimates. Similarly, the increasing need for energy efficiency in buildings demands predictive control systems that include environmental models that can be applied to diverse geographical locations. Accordingly, the validation of indoor environment models becomes essential to ensure the accuracy and robustness of the models, and consequently, their use.

Overall, the literature reveals a lack of validated models for the prediction of environmental variables in livestock buildings. Many models have been developed but not validated at all (Diesch \& Froehlich, 1988; Axaopoulos et al., 1992; Lambert et al., 2001; Besteiro et al., 2017). Other models have been validated over short periods, which does not ensure the robustness of the model or the incorporation of the effects of animal growth. For instance, Upachaban et al. (2016) validated their model for three days, whereas Liberati and Zappavigna (2007) or Seo et al. (2012), used two days for model validation and Daskalov (1997) used only one day. CFD model validation requires stable boundary conditions and this can shorten validation times even more. For the model developed by Rojano et al. (2016), the total validation time amounted to $26 \mathrm{~h} 50 \mathrm{~min}$.

Also, most authors do not considere the heterogeneity of the air volume and assume a perfect gas mixture inside the building. To predict the model output variables, these models have often used a probe or selected a specific reference spot inside the building far from the animal occupied zone, in which air volume is a key factor for environmental control. Guo et al. (2001) placed humidity and temperature probes at $1.6 \mathrm{~m}$ height above 
1 the floor, Daskalov (1997), at $1 \mathrm{~m}$ height above the floor, and Cooper et al. (1998) at $1 \mathrm{~m}$

2 below the roof. Yet, other authors have focused on the animal occupied zone (van

3 Wagenberg \& De Leeuw, 2003, Upachaban et al., 2016).

4

In addition, the input variables are not uniform. Many authors neglected the effects of solar radiation or the contribution of the evaporation of water from manure (Axaopoulos et al., 1992; Lambert et al., 2001).

The goal of this paper is to extensively validate an AutoRegressive Integrated Moving Average (ARIMA) model for the prediction of indoor temperature in the animal occupied zone of a conventional pig farm. The model, designed by Besteiro et al. (2017), predicts temperature inside a building for weaned piglets in the range 6 to $20 \mathrm{~kg}$ live body mass. The model predicts 10-min values and allows for the analysis of complete 40-day rearing cycles, which makes it suitable for use in predictive systems for climate control. Accordingly, the validated model must adapt to the increase in piglet weight and to the changes in the environmental conditions inside the building over the period of interest, which vary from $30-32^{\circ} \mathrm{C}$ for $5 \mathrm{~kg}$ live body mass to $19-25^{\circ} \mathrm{C}$ for $20 \mathrm{~kg}$ live body mass in rooms with plastic slatted floors (Muirhead \& Alexander, 1997). The model incorporates predictor variables that are representative of outdoor conditions, operation of the systems and animal weight. The 292-day validation period used allowed for analysis of model accuracy and its robustness. Accuracy was analysed by comparing model-predicted values with real values, whereas robustness was analysed in terms of the capacity of the model to maintain accuracy under different environmental and management conditions. 


\section{Materials and Methods}

\subsection{Model}

The ARIMA method is based on the assumption that past observations can explain the present and future evolution of a time series. In ARIMA models, exogenous variables related to the study dependent variable, known as predictor or independent variables, can be incorporated. There are three basic components to an ARIMA model: Auto-Regression, Integration and Moving Average. The ARIMA model investigated in this paper was designed by Besteiro et al. (2017). The model allowed for the prediction of 10-min values of animal zone temperature for a complete production cycle of approximately 6 weeks. The model included the following predictor variables: (1) the outdoor climate, as defined by outdoor air temperature $\left(T_{a o}\right),(2)$ the operation of the ventilation system, as defined by air outlet section area $\left(S_{a o}\right)$ and volume of extracted air $\left(V_{a o}\right)$ and (3) the body mass of the animals $\left(W_{a}\right)$. The most usual models of pig growth show an underlying exponential fit (Wellock et al., 2003; Vincek et al., 2012). Exponential fit was used for the three weighings performed at three different times: when the animals entered the room, when the animals left the room and at an intermediate growth stage, between days 9 and 22, in order to obtain 10-min values of animal body mass.

\section{The model shows a 2,1,2, structure $(p, d, q)$, which indicates the highest order of each} component, two backshifts for the lag order $(p)$, only one backshift for the degree of differencing $(d)$ and two backshifts for the averaging window $(q)$ of the predicted variable. The model structure shows the maximum backshifts needed for each component of the predicted variable. Table 1 shows the backshifts applied for each component ( $p, d$, q) of the study variables. Thus, the series for all the variables have been differentiated 
1 from the previous values $(d=1)$. To predict $T_{a z}$, we used the first and second backshifts

2 for the autoregressive component and only one backshift for the moving average

3 component. For the predictor variables, we used the current values and one backshift for

4 the autoregressive component. The moving average was not applied to the predictor

5 variables. From among the models developed by Besteiro et al. (2017), Model 4.4 was

6 chosen because it showed a level of significance of 0.055 , which allowed for the

7 assumption of the randomness of its residuals at a 95\% confidence level. This model was

8 the only model that described the evolution of the variable, insofar as it produced a series

9 of residuals with a structure that was similar to that of Gaussian white noise.

Table 1. Backshifts for each component, lag order $(p)$, degree of differencing $(d)$, and averaging window $(q)$ of the predicted variable, animal zone temperature $\left(T_{a z}\right) ; p$ and $d$ of predictor variables outdoor air temperature $\left(T_{a o}\right)$, air outlet section area $\left(S_{a o}\right)$, volume of extracted air $\left(V_{a o}\right)$ and animal body mass $\left(W_{a}\right)$

17

\begin{tabular}{cccccc}
\hline Component & $T_{a z}\left({ }^{\circ} \mathrm{C}\right)$ & $T_{a o}\left({ }^{\circ} \mathrm{C}\right)$ & $\left.\mathrm{Sao}_{\mathrm{com}} \mathrm{cm}^{2}\right)$ & $V_{a o}\left(\mathrm{~m}^{3}\right)$ & $W_{a}(\mathrm{~kg})$ \\
\hline$p$ & 1 & 0 & 0 & - & 0 \\
& 2 & 1 & - & - & - \\
$d$ & 1 & 1 & 1 & 1 & 1 \\
$q$ & 1 & - & - & - & - \\
\hline
\end{tabular}

\subsection{Experimental test}

To obtain the variables required for model validation, experiments were conducted on a commercial pig farm located in Northwest Spain (ED50: 43ำ10'15' 'N 8 $8^{\circ} 19^{\prime} 24^{\prime \prime}$ W). The farm, which housed weaned piglets of $20 \mathrm{~kg}$ live body mass, was representative of the type of farm found in the study area. 
1 The weaner room, with an area of $69.26 \mathrm{~m}^{2}$ and a volume of $164.50 \mathrm{~m}^{3}$, consisted of

2 twelve $2.55 \times 1.97 \mathrm{~m}$ pens, six on each side of a central aisle. The room was capable of

3 holding a maximum of 300 piglets; in this case, commercial hybrids obtained by mating

4 a Landrance-Large White F1 sow with a German Piétrain boar. The room had completely

5 slatted plastic flooring over a $450 \mathrm{~mm}$ deep pit. The ventilation system was composed of

6 a $500 \mathrm{~mm}$ helical extractor fan with $480 \mathrm{~W}$ power and an outlet section area of $0.20 \mathrm{~m}^{2}$.

7 Fan speed was adjusted by changing the voltage using a digital controller based on

8 temperature. The air outlet section area was modulated by two manually-operated sliding

9 panels according to the age of the animal. Fresh air entered the room through two 0.70

$10 \mathrm{~m}^{2}$ windows with air deflectors. The water underfloor heating system was composed of

11 two $1.20 \times 0.50 \mathrm{~m}$ polyester spreader plates for water.

To validate the model, seven production cycles with an average duration of 41.71 days were used between the $21^{\text {st }}$ of November, 2011 and the $20^{\text {th }}$ of May, 2013 (Table 2), which did not include the periods used to design the model. The following variables were measured: $T_{a z}, T_{a o}, S_{a o}, V_{a o}$ and $W_{a}$.

Temperatures were measured using an S-THB-M002 sensor (Onset Computer

Corporation $($, Bourne, MA, USA). Speed of the air extracted through the ventilation system was measured using a HD2903TTC310 (Delta Ohm, Caselle, PD, Italy) active air speed transmitter (Besteiro et al, 2017). Volume of extracted air was calculated from air velocity and fan section according to the method proposed by Hinz and Linke (1998). These variables were sampled every second and recorded at 10-min intervals. Live mass of the animals was obtained by applying the exponential growth model (Nóvak et al, 2014, Vincek et al, 2012) using the three weighings performed along the cycle. 
To determine the accuracy and robustness of the model, the differences between measured and predicted values were analysed for each validated cycle using a number of

6 statistics. The following statistics were used to determine the accuracy of the model:

- Mean Average Percentage Error (MAPE):

$8 \quad M A P E=\frac{\sum_{t=0}^{t} \frac{\left|X_{t}-\widetilde{X}_{t}\right| \cdot 100}{X_{t}}}{n}$

9 where: $X_{t}$ is the value measured at time $t, \tilde{X}_{t}$ is the value predicted by the model at time $10 \quad t$ and $n$ is the number of records.

- Mean error $(M E)$

$12 \quad M E=\frac{\sum_{t=0}^{t}\left(X_{t}-\tilde{X}_{t}\right)}{n}$

- Root mean square error (RMSE):

$R M S E=\sqrt{\frac{\sum_{t=0}^{t}\left(X_{t}-\tilde{X}_{t}\right)^{2}}{n}}$

- Coefficient of determination $\left(R^{2}\right)$

$17 \quad R^{2}=\frac{\left(\operatorname{cov}_{X \widetilde{X}}\right)^{2}}{\sigma_{X}^{2} \sigma_{\widetilde{X}}^{2}}$

where: $\operatorname{COV}_{X \tilde{X}}$ is the covariance of $X$ and $\tilde{X}, \sigma_{X}$ is the standard deviation of $X$, and $\sigma_{\tilde{X}}$ is

19 the standard deviation of $\tilde{X}$.

The parameters and structure of the ARIMA model were estimated using the Expert Modeler module included in SPSS Statistics 19 (SPSS Inc., Chicago, IL, USA). 


\section{Results}

Table 2 shows the means and standard deviations of 10-min measurements of the predictor variables for each validated cycle, namely outdoor air temperature $\left(T_{a o}\right)$, air outlet section area $\left(S_{a o}\right)$, volume of extracted air $\left(V_{a o}\right)$ and animal weight $\left(W_{a}\right)$. Mean outdoor air temperatures were in the range 6.14 to $17.85^{\circ} \mathrm{C}$ with deviations between $2.49^{\circ} \mathrm{C}$ and $5.24^{\circ} \mathrm{C}$. Such variations involved marked differences in the operation of the ventilation system, with air outlet section areas between $0.080789 \mathrm{~m}^{2}$ and $0.173724 \mathrm{~m}^{2}$, and a mean volume of extracted air between 110.45 and $457.85 \mathrm{~m}^{3}$. Volume values were sampled at 10 -min intervals. The average body mass of piglets was $5.75 \pm 0.86 \mathrm{~kg}$ at the beginning of the cycle and $18.41 \pm 2.12 \mathrm{~kg}$ at the end of the cycle, with an average daily gain of $0.300 \pm 0.038 \mathrm{~kg} \mathrm{day}^{-1}$.

Table 2. Cycle number, cycle dates and durations, and mean and standard deviation $(S D)$ values of 10-min data of outdoor air temperature $\left(T_{a o}\right)$, air outlet section area $\left(S_{a o}\right)$ and volume of extracted air $\left(V_{a o}\right)$

\begin{tabular}{|c|c|c|c|c|c|c|c|c|}
\hline \multirow{2}{*}{ Cycle } & \multirow{2}{*}{$\begin{array}{c}\text { Animal entry } \\
\text { date }\end{array}$} & \multirow{2}{*}{$\begin{array}{c}\text { Cycle } \\
\text { duratio } \\
n \text { (d) }\end{array}$} & \multicolumn{2}{|c|}{$T_{a o}\left({ }^{\circ} \mathrm{C}\right)$} & \multicolumn{2}{|c|}{$S_{a o}\left(\mathrm{~m}^{2}\right)$} & \multicolumn{2}{|c|}{$V_{a o}\left(\mathrm{~m}^{3}\right)$} \\
\hline & & & Mean & $S D$ & Mean & $S D$ & Mean & $S D$ \\
\hline 1 & $21 / 11 / 2011$ & 43 & 8.86 & 2.49 & 0.080789 & 0.044055 & 110.45 & 54.03 \\
\hline 2 & 09/01/2012 & 43 & 6.14 & 3.16 & 0.093501 & 0.056685 & 145.16 & 75.58 \\
\hline 3 & $27 / 02 / 2012$ & 38 & 11.38 & 5.24 & 0.125439 & 0.043898 & 221.21 & 224.46 \\
\hline 4 & $12 / 04 / 2012$ & 40 & 10.43 & 4.35 & 0.090795 & 0.058367 & 171.15 & 161.98 \\
\hline 5 & $31 / 05 / 2012$ & 44 & 15.58 & 4.37 & 0.168623 & 0.095329 & 457.85 & 420.53 \\
\hline 6 & $19 / 07 / 2012$ & 44 & 17.85 & 4.12 & 0.173724 & 0.093626 & 397.59 & 354.69 \\
\hline 7 & $11 / 04 / 2013$ & 40 & 10.38 & 4.22 & 0.151489 & 0.082696 & 204.04 & 138.23 \\
\hline
\end{tabular}

20 Validation of the model for the different cycles showed high accuracy (Table 3).

21 MAPE values were low, always below $4 \%$, with a $M E$ of $\leq 1^{\circ} \mathrm{C}$. The $R M S E$ values for the different cycles were between $0.77^{\circ} \mathrm{C}$ for cycle 7 and $1.19^{\circ} \mathrm{C}$ for cycle 2 , and maintained 
1 an average accuracy of $0.99^{\circ} \mathrm{C}$ throughout the validated cycles. The coefficient of

2 determination ranged from 0.52 for cycle 1 to 0.81 for cycle 7 . The analysis of the

3 variability of accuracy for the different cycles revealed that accuracy remained stable and

4 with low dispersion of values despite environmental and management changes.

5

Table 3. Errors obtained from cycle validation for animal-zone temperature.

7 Mean Absolute Percentage Error (MAPE), Mean Error (ME), Root Mean Square

8 Error (RMSE) and coefficient of determination $\left(R^{2}\right)$

\begin{tabular}{lllll}
\hline Cycle & MAPE $(\%)$ & $M E\left({ }^{\circ} \mathrm{C}\right)$ & $R M S E\left({ }^{\circ} \mathrm{C}\right)$ & $R^{2}$ \\
\hline 1 & 2.62 & 0.46 & 0.86 & 0.52 \\
2 & 3.82 & 1.01 & 1.19 & 0.77 \\
3 & 3.32 & 0.85 & 1.11 & 0.64 \\
4 & 2.27 & 0.15 & 0.78 & 0.72 \\
5 & 3.48 & -0.58 & 1.13 & 0.72 \\
6 & 3.26 & -0.48 & 1.09 & 0.71 \\
7 & 2.39 & -0.05 & 0.77 & 0.81 \\
\hline
\end{tabular}

9

\section{Discussion}

Most of the models for the prediction of indoor environment variables inside livestock

buildings found in the literature are aimed at estimating the ventilation rate needed to obtain suitable values of temperature, relative humidity and pollutant concentrations. To date, models for the prediction of indoor temperature have been seldom validated.

The statistical model designed by Daskalov (1997) for weaned piglet buildings with natural ventilation measured temperatures at $1 \mathrm{~m}$ above the floor and obtained an $M E$ of

$1.12^{\circ} \mathrm{C}$. Compared to this value, the values reported in this paper are in the range -0.05 to $1.01^{\circ}$ and therefore offer a substantial improvement. The model validation conducted by Daskalov (1997) used 720 records that consisted of average temperatures measured at 
1 2-min intervals during three 8-h experiments carried out in winter, summer and spring,

2 which amounted to $24 \mathrm{~h}$ of discontinuous measurements. By contrast, this model covers

3 seven complete production cycles that amount to $292 \mathrm{~d}$.

4

Schauberger and Pilati (1998) validated an analytical model for temperature estimation based on steady-state balances of sensible heat, humidity and $\mathrm{CO}_{2}$. Such models have been widely used to calculate air exchange rates (Blanes \& Pedersen, 2005; Garcimartín et al., 2007; Samer et al., 2011). Schauberger and Pilati (1998) used the hourly average indoor temperature values recorded in a cattle building with natural ventilation over 51 d. An $M E$ of $-1.40^{\circ} \mathrm{C}$ was obtained, with an overestimation of indoor temperature, which is in agreement with our results for cycles 5, 6 and 7, but with a greater magnitude of error.

Other authors have proposed analytical methods for indoor temperature predictions that rigorously analysed the variables included in the model. Cooper et al. (1998) developed a model to calculate hourly steady-state heat balances in naturally ventilated livestock buildings, but neglected animal heat. Average temperatures were measured at nine locations at a height of $1 \mathrm{~m}$ below the roof. To validate the model, 168 records were used. The mean absolute error was $0.41^{\circ} \mathrm{C}$, with a magnitude similar to that of the values reported here. Yet, the validation was performed in a building with good natural ventilation using fewer records.

Van Wagenberg et al. (2004) focused on the animal occupied zone in a pig building with forced ventilation. They measured temperature at 10 -min intervals at $0.15 \mathrm{~m}$ height and $0.05 \mathrm{~m}$ distance from the pen partitions, such that sensor location was very similar to 
1 the locations used in our study. The numerical model was validated for three hours, one

2 hour a day, with piglets of an approximate average body weight of $13.10 \mathrm{~kg}$. The $M E$

3 reported by van Wagenberg et al. (2004) for the validation of the model was $0.83^{\circ} \mathrm{C}$,

4 which is close to the maximum errors obtained for complete cycles in our validation.

6 The CFD model proposed by Seo et al. (2012) measured temperature at $1 \mathrm{~m}$ above the

7 floor in a commercial pig building with forced ventilation that housed pigs from 20 to 50

$8 \mathrm{~kg}$ live body mass. A 20 -h validation of the model yielded an $M E$ of $-0.68^{\circ} \mathrm{C}$ and an MAPE of -4.4\%. Also, Rojano et al. (2016) developed a computational model of thermal gradient for a naturally ventilated poultry house. The experimental and simulated datasets contained 90 values obtained at 15 locations with 6 measurements each. Results yielded RMSE values between 0.5 and $1.3^{\circ} \mathrm{C}$. In both models, the validation period required stable outside conditions. These simulations provide a large amount of data about the

Upachaban et al. (2016) validated a physical heat and moisture balance model for three days and compared the predicted temperatures with the temperatures measured at $0.3 \mathrm{~m}$ height at three locations along a closed-poultry house. The results showed RMSE values between 0.46 and $1.77^{\circ} \mathrm{C}$, which is in agreement with the results reported in this paper.

The validations of the reviewed models were performed for very short periods and, generally, using discontinuous measurements. In contrast, our model was validated for 292 d, using over 36000 records of continuous measurements. Except for the models developed by van Wagenberg et al. (2004) and Upachaban et al. (2016), the aim of the 
1 models discussed was to predict indoor temperature outside the animal occupied zone.

2 However, prediction of indoor temperatures is more meaningful in the animal occupied

3 zone where suitable conditions for growth need to be guaranteed.

Predictions in our model are based on previous data of indoor temperature and the predictor variables, namely outdoor air temperature, outlet section area, volume of extracted air and animal weigh, which can be easily measured. In addition, this method is applicable because determining the values of these variables is a part of farm management routines. In addition, model validation during 7 cycles under different robustness and accuracy of the model.

Also, the model can adapt to the substantial variations in the environmental requirements observed during this stage of breeding (Le Dividich \& Herpin, 1994; Dong \& Pluske, 2007), which result from the increase in animal weight in a very short time (e.g. 6 weeks). Finally, this dynamic, rapid-response model (10-min) is highly useful for the analysis and optimization of ventilation and heating systems, in spite of the higher inertia of heating.

It should be noted that the model investigated here has been designed for one particular barn set-up in one particular set of climatic challenges, which limits its use to only the validation conditions. However, ARIMA modelling can be used to obtain reliable models for buildings with other facilities or under other climatic conditions using similar predictors (outside temperature, ventilation and animal weight).

The generation of our model provides a 0.55 level of significance for the Ljung-Box statistic, which allows for the assumption of the randomness of its residuals at $95 \%$ 
1 confidence level (Besteiro et al., 2017). As a result of error randomness, no clear trends

2 were found for the errors in predictions. For instance, during the first period, both

3 underestimations (cycles 2, 3, 4) and overestimations (cycles 1, 5, 6) are found (Fig. 1).

4 Important temperature changes (Fig. 2.) often result in underestimations, particularly

5 under high temperatures (Cycle 4), but also in overestimations (Cycle 5) or good fits

6 (Cycle 7). Similarly, different responses have been observed under slight temperature

7 changes (Fig. 3). Consequently, analyzing the errors becomes essential.

8

9 According to the graphical analysis of the distributions of residuals obtained from 10 model validation, residuals tend to be Gaussian (normally) distributed, although the 11 distributions obtained from prediction residuals are not identical to those of Gaussian white noise (Fig. 4). The $M E$ values suggest that the distributions of residuals for the cycles with average temperatures (cycles 4 and 7) are almost centred on zero. By contrast, during the cold cycles (1 and 2), the distribution of histograms was skewed to the right,

15 i.e., temperature is underestimated (positive $M E$ ), whereas during the warm cycles (6 and 16 7), the distribution is skewed to the left (negative $M E$ ). Accordingly, there appears to be some dependence between residuals and outdoor temperature, which in turn affects the operation of the ventilation system, both included as predictor variables in the model. However, overall the errors were quite symmetrically distributed. For cycles 2 and 6 , the central area of the histogram is slightly skewed. This behaviour is more frequent for the values near and below the mean.

\section{Conclusion}


1 The statistical model validated in this paper provides a relevant improvement in terms

2 of accuracy and reliability compared to the existing models because of its extensive and

3 continuous validation under changing meteorological conditions and because it considers

4 the operation of the heating and ventilation systems, as well as changes due to animal

5 body mass. However, the model predicts only the temperature of the building, whereas

6 numerical models can provide a more detailed description under stable conditions for

7 short periods. The residuals obtained from the validation of the seven production cycles

8 can be considered to be Gaussian (normally) distributed, which confirms the validity of

9 the model. The generated model can be used in more effective environmental control

10 systems that are capable of anticipating events and show a better response, which can

11 improve energy savings and animal welfare.

Acknowledgment research units" (GPC2014/072).

\section{References}

Axaopoulos, P., Panagakis, P., \& Kyritsis, S. (1992). Computer simulation assessment of the thermal microenvironment of growing pigs under summer conditions. Transactions of the ASAE, 35(3), 1005-1009. doi: 10.13031/2013.28694. modeling of animal zone temperature in weaned piglet buildings: design of the model. 
1 Blanes, V., \& Pedersen, S. (2005). Ventilation flow in pig houses measured and calculated by

2 carbon dioxide, moisture and heat balance equations. Biosystems Engineering, 92(4), 483-493.

3 https://doi.org/10.1016/j.biosystemseng.2005.09.002.

4 Cooper, K., Parsons, D. J., \& Demmers, T. (1998). A thermal balance model for livestock

5 buildings for use in climate change studies. Journal of Agricultural Engineering Research,

6 69(1), 43-52. https://doi.org/10.1006/jaer.1997.0223.

7 Daskalov, P. I. (1997). Prediction of temperature and humidity in a naturally ventilated pig

8 building. Journal of Agricultural Engineering Research, 68(4), 329-339.

9 https://doi.org/10.1006/jaer.1997.0211.

Diesch, M. A., \& Froehlich, D. P. (1988). Production and environmental simulations in

11 livestock housing. Transactions of the ASAE, 31(5), 1532-1539. doi: 10.13031/2013.30896.

Dolz, N., Babot, D., Alvarez-Rodriguez, J., \& Forcada, F. (2015). Improving the environment for weaned piglets using polypropylene fabrics above the animals in cold periods. International Journal of Biometeorology, 59(12), 1839-1847. https://doi.org/10.1007/s00484-015-0991-0.

Dong, G. Z., \& Pluske, J. R. (2007). The low feed intake in newly-weaned pigs: problems and possible solutions. Asian-Australasian Journal of Animal Sciences, 20(3), 440-452. https://doi.org/10.5713/ajas.2007.440.

Garcimartin, M. A., Ovejero, I., Sanchez, E., \& Sanchez-Giron, V. (2007). Application of the sensible heat balance to determine the temperature tolerance of commercial poultry housing. World's Poultry Science Journal, 63(4), 575-584. https://doi.org/10.1017/S0043933907001626. swine buildings in cold climate - Part II: Development and evaluation of a humidity controller. Canadian Biosystems Engineering, 43, 537-546 
1 emissions from livestock buildings. Part 1: Methods. Journal of Agricultural Engineering

2 Research, 70(1), 111-118. https://doi.org/10.1006/jaer.1997.0279.

3 Lambert, M., Lemay, S. P., Barber, E. M., Crowe, T. G., \& Chénard, L. (2001). Humidity

4 control for swine buildings in cold climate- Part I: Modelling of three control strategies.

5 Canadian Biosystems Engineering, 43(5), 529-536.

6 Le Dividich, J., \& Herpin, P. (1994). Effects of climatic conditions on the performance,

7 metabolism and health status of weaned piglets: a review. Livestock Production Science, 38(2),

8 79-90. https://doi.org/10.1016/0301-6226(94)90052-3.

9 Liberati, P., \& Zappavigna, P. (2007). A dynamic computer model for optimization of the

10 internal climate in swine housing design. Transactions of the ASABE, 50(6), 2179-2188. doi:

$11 \quad \underline{10.13031 / 2013.24093 .}$.

12 Muirhead, M. R., \& Alexander, T. J. L. (1997). Managing pig health and the treatment of

13 disease: a reference for the farm. (1st ed.). Shefield. 5M Enterprises Ltd., (Chapter 3).

Novák, L., Zeman, L., Novák, P., \& Mareš, P. (2014). Modeling the pigs body mass growth and the stressing factors impact on the daily feed intake. Acta Universitatis Agriculturae et Silviculturae Mendelianae Brunensis, 53(5), 105-116. http://dx.doi.org/10.11118/actaun200553050105

Rojano, F., Bournet, P. E., Hassouna, M., Robin, P., Kacira, M., \& Choi, C. Y. (2016). Computational modelling of thermal and humidity gradients for a naturally ventilated poultry house. Biosystems Engineering, 151, 273-285.

21 https://doi.org/10.1016/j.biosystemseng.2016.09.012. (2011). Heat balance and tracer gas technique for airflow rates measurement and gaseous emissions quantification in naturally ventilated livestock buildings. Energy and Buildings, 43(12), 3718-3728. https://doi.org/10.1016/j.enbuild.2011.10.008. 
1 Seo, I. H., Lee, I. B., Moon, O. K., Hong, S. W., Hwang, H. S., Bitog, J. P., Kwon, K. S., Ye,

2 Z., \& Lee, J. W. (2012). Modelling of internal environmental conditions in a full-scale

3 commercial pig house containing animals. Biosystems Engineering, 111(1), 91-106.

$4 \quad$ https://doi.org/10.1016/j.biosystemseng.2011.10.012.

5 Schauberger, G., \& Pilati, P. 1998. Evaluation of a steady-state balance model to simulate the

6 indoor climate in livestock buildings: A comparison with measurements of a cattle house.

$7 \quad$ Wiener Tierarztliche Monatsschrift, 85(2), 49-55.

8 Upachaban, T., Khongsatit, K., \& Radpukdee, T. (2016). Mathematical model and simulation

9 study of a closed-poultry house environment. Mechanical Engineering, 7, 1246-1252.

10 https://doi.org/10.14716/ijtech.v7i7.4744.

11 van Wagenberg, A. V., \& de Leeuw, M. T. J. (2003). Measurement of air velocity in animal

12 occupied zones using an ultrasonic anemometer. Applied Engineering in Agriculture, 19(4),

13 499-508. doi: 10.13031/2013.14922.

14 van Wagenberg, A. V., Bjerg, B., Bot, G. P. A., 2004. Measurements and simulation of climatic

15 conditions in the animal occupied zone in a door ventilated room for piglets. Agricultural

16 Engineering International: The CIGR Journal of Scientific Research and Development,

17 Manuscript BC 03 020, Vol VI.

18 Vincek, D., Sabo K., Kušec G., Kralik G., Durkin I., \& Scitovski, R. (2012). Modeling of pig

19 growth by s-function-least absolute deviation approach for parameter estimation. Archives of

20 Animal Breeding, 55 (4): 364-74. https://doi.org/10.5194/aab-55-364-2012.

21 Wellock, I. J., Emmans, G. C., \& Kyriazakis, I. (2003). Modelling the effects of thermal

22 environment and dietary composition on pig performance: model logic and concepts. Animal

Science, 77, 255 - 266. https://doi.org/10.1017/S1357729800058999. 


\section{Figure Captions}

2

3 Fig. 1. Measured (discontinuous) and simulated (continuous) temperatures in the animal $4 \quad$ zone for the first three days

5 Fig. 2. Measured (discontinuous) and simulated (continuous) temperatures in the animal 6 zone for periods with important temperature changes

7 Fig. 3. Measured (discontinuous) and simulated (continuous) temperatures in the animal $8 \quad$ zone for periods with slight temperature changes

9 Fig. 4. Distribution of residuals of temperature in the animal zone $\left({ }^{\circ} \mathrm{C}\right)$ for the validated 10 production cycles 